\title{
Networks of public open spaces in the urban fabric
}

\author{
E. Aga \\ School of Rural and Surveying Engineering, \\ National Technical University of Athens, Greece
}

\begin{abstract}
Today, much emphasis is placed on the ecological dimension of architectural and town planning, focusing on the relationship between humans and the environment. Outdoor public spaces are a prominent element in physical planning structures, firstly because it is within them that the public life of their users may develop - they in fact serve to maintain an equilibrium between the private and public spheres in the cities - and secondly because with suitable planning they can provide environmentally-friendly natural inputs. A central open public area can function as the heart of a city. A whole network of open spaces, suitably interlinked and extending throughout the urban fabric, goes further, imparting vigour to all parts of it. Such open spaces comprise a totality that is something more than the sum of its components. Networks of open spaces in the historic cities of Venice (Italy), Venice Canals (L.A.), Savannah (Georgia), and Folegandros (Greece) are outstanding individual examples tending to confirm the above thesis. It has been verified that the balanced proliferation of open public spaces can create a comprehensible network and constitute an important element in their identity. The purpose of the following article is to document the importance of suitably planned polycentric structures, the crucial element being their relations of mutuality and their linkage with the cities not only of the present but also of the future.
\end{abstract}

Keywords: network, urban fabric, open public spaces, legibility, livability, identity. 


\section{Introduction}

The element that determines the sustainability of a city and shapes its orientation towards conservation is not its economic vigour, the degree to which its economy is being developed and extended, but its livability. "...What is sustained is the web of life on which our long-term survival depends, in other words, a sustainable community is designed in such a way, that its ways of life, its technologies and its social institutions honor and support and co-operate with nature's inherent ability to sustain life" (Capra 2007).

The open spaces for expression of the public life of the inhabitants of a residential ensemble are a significant indicator for sustainability. The diffusion of public open spaces through the urban fabric, and the interaction between them, should serve to maintain a balanced relationship between the private and the public. Scale, identity, variety, in functions, greenery, materials, livability: these are vital characteristics of healthy and durable cities. The demand for urban sustainability has become particularly pertinent in recent decades. Disruption of the balance between public and private life to the disadvantage of the former, changes of scale in cities as a result of their rapid expansion within the space of a few years, lack of coherence between the private and public realms, the multicultural character of societies that has resulted from continual population movement, inequalities between residents in their ability to use public space: these are questions to which the answers must be of planetary resonance and to which indeed answers must be given. Interventions that are piecemeal, failing to take into account the dynamics of the city as a whole, are inevitably ineffectual.

A crucial subject for architects and town-planners is upgrading of the public sphere in cities and in residential ensembles, the creation of autonomous but also mutually complementary public spaces extending in a balanced manner into the urban fabric and linking up in such a way as, ultimately, to constitute a whole, an accessible network of vital enclaves, free from social exclusion, not merely supporting public life but offering the prerequisites for action, creativity and further development.

One promising method for approaching the multifarious problems of today's cities, inhospitable as they are in so many ways, is to undertake a rethinking of a past that endures into the present, illuminating the future. I shall endeavour in this article to give a reading and an interpretation of the public sphere in four living historical cities, by common consent particularly attractive and vital places, namely Venice (Italy), Savannah (Georgia, U.S.A.), Folegandros (Greece) and Venice Canals (Los Angeles, California, U.S.A.). All of them models of perennial durability, continuity and adaptability to the changing needs and demands of the times. Our goal is to coax out the elements serving to highlight the virtues of endurance and vitality, arrange them in groupings and finally put them forward, not as rules but as a framework for intervention, whether in existing cities or in the new cities to be created. 


\section{Natural growth and systematic plan}

Town planning has been practiced since ancient times [1]. Cities that have "planned themselves" and cities that have been planned have coexisted throughout history. In Alexander's formulation, those cities that have arisen spontaneously over many, many years are "natural cities", whereas those cities or parts of cities that have been deliberately created by planners are "artificial cities". In the creation of "natural cities" the absence of rules, the free elaboration of the urban fabric, are the product of spontaneity. By contrast, in the case of "artificial cities", the logic of planning - a systematized and quite specific way of organizing thought - entails formal representation of a particular kind of functional demand.

The four cities to be examined in this article belong to both categories. Venice (Italy), and Folegandros (Greece) are natural cities, Savannah (Georgia) and Venice (California) are "artificial cities". This in itself suggests that natural cities are at no advantage over planned cities when it comes to sustainability. "Whereas any city can be analyzed and understood as an ecosystem, 'ecological city' is a term intended to identify a particular type of city.... The most important aspect of the city form in this respect may in fact be density, as a sprawling city of any type is harder to service efficiently. Pedestrian accessibility, complexity and internal interconnectivity all strongly correlate with density. They are characteristics that could be elaborated out of virtually any typology." [2].

\subsection{The structure of the urban fabric, historical data}

\subsubsection{The natural formation}

Cities that have originated as natural formations are typically organized around a centre, either in a longitudinal arrangement or in clusters. The topography and the organization of open spaces, the cohesive character of the built-up areas, are basic structural elements of the urban fabric. The clarity of its structure, the accessibility of the public areas, are intrinsically vitalizing in their effect on the cities. Examining the two European examples of natural cities, we note the following:

Venice (Italy): The morphology of the city of Venice, with its centuries-old uninterrupted history (from the $9^{\text {th }}$ century to the present), its magnificent, universally-known and much-frequented St. Mark's square and the Grand Canal with its countless palazzi, is in a category of its own, constructed upon the lagoon of the same name, with the result that pedestrians and small craft (vaporetti, gondolas) are the only traffic. The opaque character of the urbanabric is evidenced by the following: densely populated small islands (more than 100), labyrinthine thoroughfares with bridges, canals (over 150), scattered open spaces in the different neighbourhoods (more than 30 campi and campielli) (figs. 1,2).

Folegandros (Greece): Historically the first residential district is Kastro, which preserves its plan unchanged from 1577 (fig.3). It was built at the edge of a 200-metre-high cliff to afford it security in the face of attacks from the sea. It belongs in the category of fortified settlement, with its open public spaces also 
62 The Sustainable World

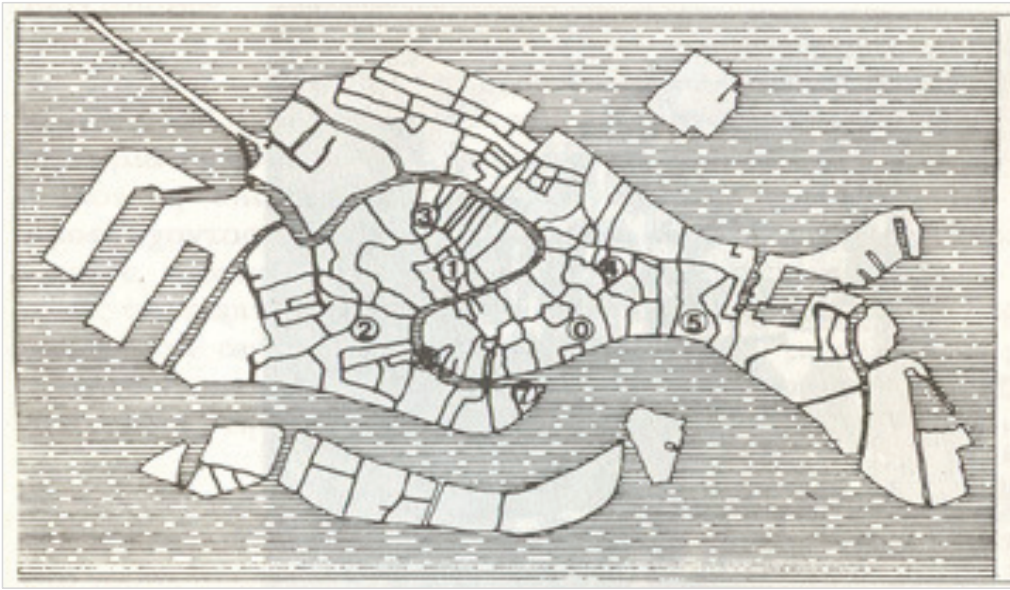

Figure 1: $\quad$ Map of Venice.

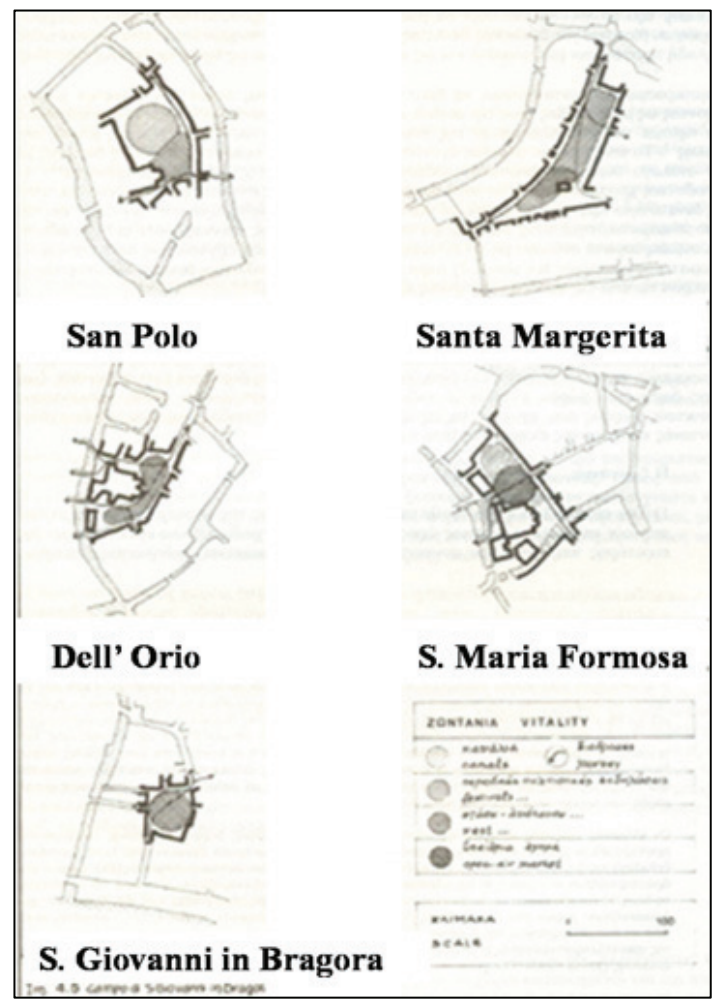

Figure 2: $\quad$ Indicative campi. 
serving as thoroughfares for vehicular traffic. The extension of the built-up area of Chora outside Kastro and contiguous to it was constructed at the beginning of the $18^{\text {th }}$ century (1720), in phases and without any systematic plan. The first new structures to appear around Kastro were mostly churches, built not far from it, as the fear of attackers had not yet entirely receded. Non-religious buildings were grouped around the religious buildings, resulting in the creation of large open but enclosed public spaces for gathering together the inhabitants and providing relief from their daily routine. Six open squares, one after the other, six consecutive settings for display of the local heritage in traditional architecture, form the backbone of central Chora. They are the terrain for the social activity of residents and visitors alike (fig. 4).

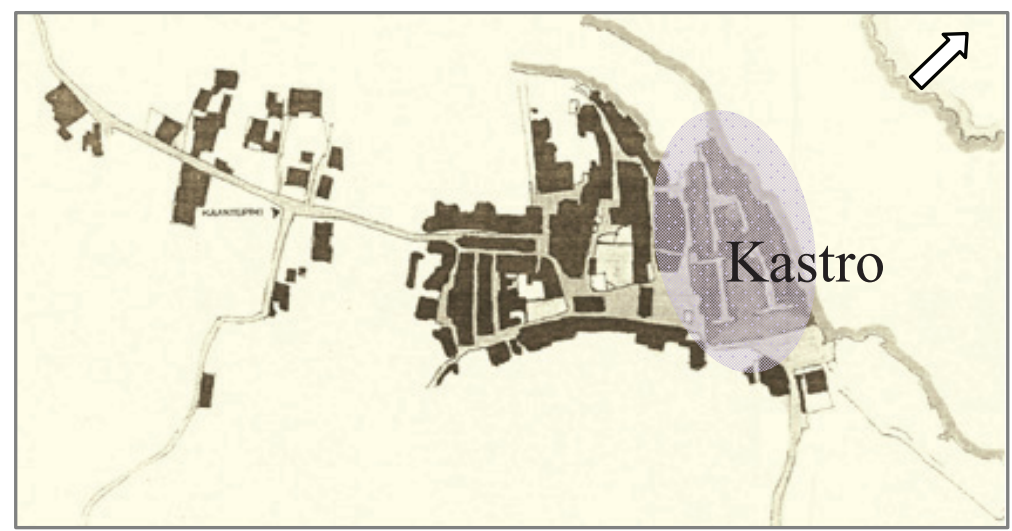

Figure 3: Chora, Folegandros.

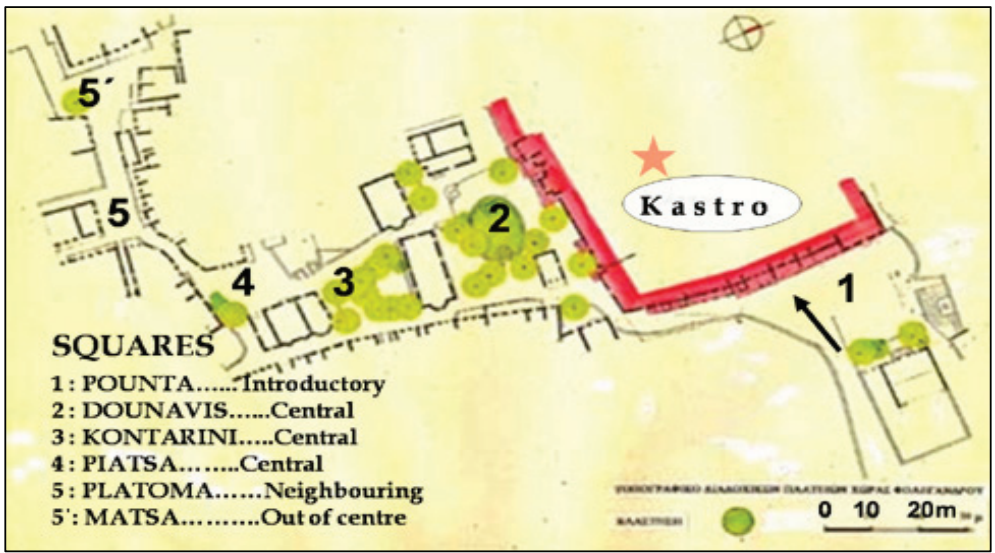

Figure 4: Squares of Chora. 


\subsubsection{Systematic plan}

In systematically planned cities (as indeed in cities that spring up spontaneously) the structural elements of the urban fabric are: the topography of the residential environment, the layout and arrangement of the open architectural shells. Geometric regularity in outlining of the urban fabric simplifies interpretation of the picture from the outset. Specifically, in the two examples from the U.S.A. the following are noted:

Savannah (Georgia, U.S.A.): The urban fabric possesses homogeneity and regularity in its layout, in keeping with the Hippodameian system from which it derives (fig. 5). The city was founded by James Edward Oglethorpe on flat land beside the Savannah River from which it takes its name, subsequently undergoing a succession of growth phases, to which the ages of the public squares correspond.

Twenty-two public squares were included within the level expanse, three square kilometres in area, of Savannah's historic centre. In accordance with the town plan these occupied the centres of characteristically recurring units known as "wards" [3]. A mesh of roads marked out along N/S, E/W perpendicular axes traverses the grid of wards, encircling the squares but not passing through them (fig. 6).

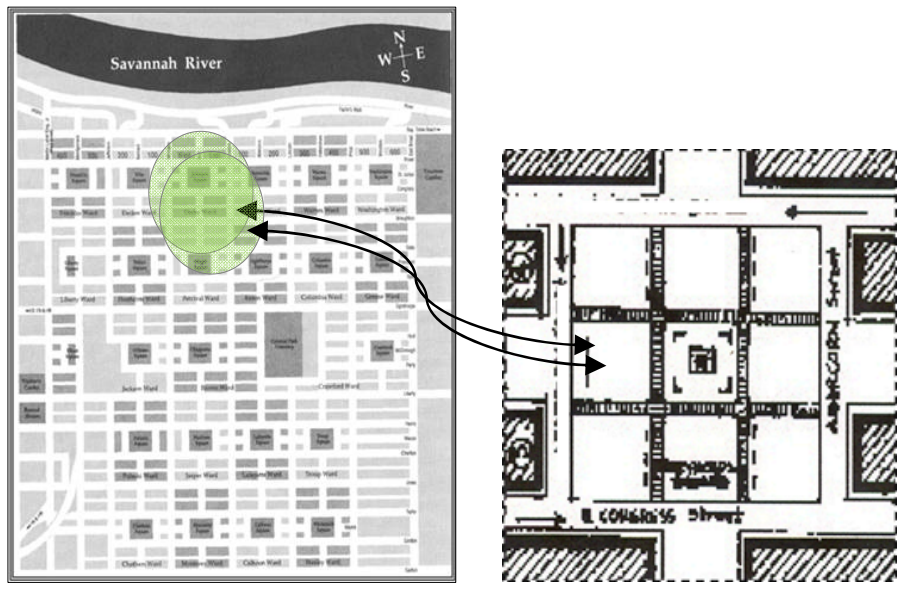

Figure 5: Map of Savannah.

Figure 6: 'Ward'.

Venice (California, U.S.A.): The city was conceived and established in 1905 by the tobacco magnate Abbot Kinney, influenced by his impressions from travel in Europe. On the model of Venice in Italy he conceived of a seaside resort and pleasure ground criss-crossed by canals 28 kilometres in length. Today, after many decades of decline, Venice is a centre for bohemian personal expression in Southern California. From the original plan of 1905 there is preserved only the small historic residential neighbourhood of Venice Canals, with canals around two kilometers in length. The first houses to be built on the canals were downmarket summer holiday cottages (bungalows) (figs. 7, 8). 


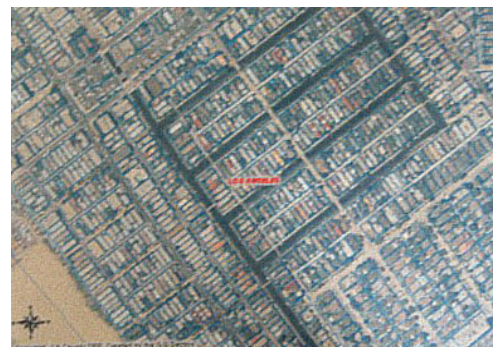

Figure 7: Venice, aerial photo.

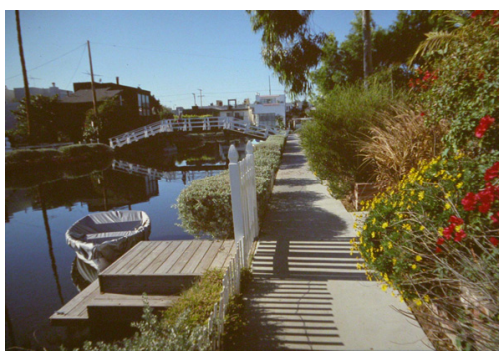

Figure 8: $\quad$ Canal in Venice.

\subsection{Network of public open spaces, Interconnection - visual communication}

The predominant element in the planning scheme of the four specimen cities, irrespective of the regularity or non-regularity of their layout, is the equal distribution of a variety of vital public open spaces linked together by access routes for pedestrians and constituting networks. The unbroken chain of access routes to be traversed on foot or by boat unites all the scattered public areas into an ensemble, in effect comprising the public space of these cities. The four cities share the following distinctive characteristics:

Venice (Italy): Dispersion and decentralization of over thirty open public spaces (campi) within the densely built-up urban fabric is the sole existing mode of organization of the public realm. Embedded as they are in the midst of the city's labyrinthine fabric, the campi are not in visual contact with each other. It would nevertheless not be appropriate to call them isole (islands) in the sense of being isolated, because they do communicate with each other, linked via a network of winding passageways exclusively for pedestrians. The complex layout of the flat, densely-built-up island of Venice that rises out of the lagoon is exceptionally opaque, by no means easy for anyone to commit to memory. But penetration into the fabric of the "city of pedestrians" is rewarded by the experience of the numerous campi, enclaves where the rhythms of day-to-day life continue as before, injecting vitality into all the city's neighbourhoods. An exploratory stroll in them evokes sensations of intense contrast at the transition from narrow dimly lit alleyways to the open spaces of the camp (darkness light, narrowness - space), agreeable revelations (limitation - freedom) and above all a unique wealth of impressions.

Folegandros (Greece): One distinctive feature of Chora, the traditional settlement with its level, accessible, pedestrian-friendly physiognomy, is the proportionately large open public spaces. The straight-line perspectives of the successive public squares contribute to forming an unbroken continuum of easily comprehended and aesthetically memorable public open spaces. Like a succession of landscapes engraved in miniature the squares unfold one after another along a pedestrian axis that is like the backbone of the settlement and from which wheeled vehicles have been excluded. Movement in the environs of the squares takes place before the eyes of the public and the traffic flow is 
continuous. The sequential encounter with the squares evokes in pedestrians a sense of pleasurable anticipation, giving way to surprise at the squares' unusual diversity. The impressions created by each square are influenced by those preceding it and in turn influence those succeeding it.

Savannah (Georgia, U.S.A.): The basic features in the architectural layout of the city's historic centre are its regular geometrical formation, the equal distribution of public space throughout the entire expanse of the old city, the abundant greenery, the visual transparency and openness of communication between the 22 public squares, the spatial and temporal orientation and the priority afforded to pedestrians over automobiles. The uniform character of the network of public squares, each of them like a small oasis, is a significant privilege for a city in the warm and humid South of the United States, constituting a challenge and an invitation to linger in them. The pedestrian circulation, the channeling of movement towards low-traffic-density roads, the visual communication between the squares, all these factors generate a pleasing sense of anticipation and a variety of impressions from the different individual aspects of the form and content of each square.

Venice canals (California, USA.): The final example has to do with a historic and exclusively residential neighbourhood. Its predominating feature is one of absolute equality and absolute egalitarianism in designation of public and private space. The rectangular layout of the network of linear and open public locations in the canal neighbourhood is an all-pervasive element, making it possible for movement to be entirely on foot or entirely by boat, for visual communication to exist between the enclaves, and for there to be utilization and full highlighting of the built-up areas. The network of canals bordering the property of the residents, extending the private open space, projects, the image of a uniform ensemble of open spaces around flowing water. The enclosed layout, the austere geometry of the canals and the parallel movements of their users, from this direction, from that direction, beside the waters, provide escape-routes that captivate the attention, orient movement, facilitate comprehension, utilization and enjoyment of the public space in a unique historic residential neighbourhbood.

Differences in the physiognomy of the squares had to do essentially with geographical features, topography, political, economic and historical context, with their developmental trajectory, architectural physiognomy and identity. Here we propose to underline the elements that are linked to elaboration of the town plan, the squares and their most prominent characteristics.

\section{Final comments - the whole and the part}

Public open spaces: streets, squares, greens - these are the commons of the city. In present-day cities the desideratum is that there should be a network of living open spaces able to reveal the public realm to the roving observer. Lord Rogers says "... to achieve urban integration means thinking of urban open space not as an isolated unit-be it a street, park or square - but as a vital part of urban landscape with its own specific set of functions. Public space should be conceived of as an outdoor room within a neighbourhood, somewhere to relax, 
and enjoy the urban experience, a venue for a range of different activities, from outdoor eating to street entertainment; from sport and play areas to a venue for civic or political functions; and most importantly of all a place for walking or sitting-out. Public spaces work best when they establish a direct relationship between the space and the people who live and work around it". [4].

The diffusion and the linking together of places in a "Legato" (linkage, from the musical term meaning connected) movement are among the virtues of the public sphere as manifested in the cities under discussion, which belong in both the "natural" and the "systematically planned" categories. Their networks of public space generate organic wholes, in the framework of which public spaces function as centres - poles of attraction and points of intersection for a variety of paths, constituting a whole that is more than the sum of its parts. The diffusion of living public open space over all the expanse of a city for a start demonstrates a democratic outlook and a disposition to make use of all possible areas as enclaves of public life with the ability also to function as the city's "lungs". The "Legato" of the individual building complexes is a prerequisite for the sustainability of the specimen cities. The mode of effecting the linkage differs in all four cases, but there are the common factors not only of decentralization but also of linkage for pedestrian traffic in a continuous band.

Open public spaces generate continuities and discontinuities. The degree of proximity to each other of the open architectural shells, the way in which their style of interaction also determines their mode of composition as a unified ensemble. "The natural and anthropogenic elements of impermeable matter shape space, but this space cannot be regarded as conceptually neutral, nor absolutely empty. There are visible forces of attraction and repulsion running through it, with their origins in the size and the shape of structural elements, and all together constituting a kind of field. The space between the two constructs appears denser or sparser depending on the size and shape of the intervening space they define" [5]. In existing urban fabrics, the networking-cum-unification of open spaces can act as an effective medium for reinvigorating them. The visual conception of a coherent image of spaces, monuments or building clusters facilitates spatial and temporary orientation and the highlighting of distinctive elements in the physiognomy of a city. The linking up of the archaeological sites inside the urban fabric of present-day Athens, in view of Greece's hosting the Olympic Games in 2004, aimed at projecting the elements of the city's identity in Classical and Hellenistic times. A daily walk in these districts is evidently not only enjoyable and enlightening for visitors but also refreshing for the resident of the city, presenting as it does another picture of Athens.

The unfailing vitality of open public spaces over time testifies to the evolutionary course of a past which has a present and a future. A culture of public life is required if the city's public face is to be recaptured. What is required is a systematic endeavour anchored in an upgrading and a highlighting of the intervening spaces, planning, not the piecemeal and fragmentary, not isolated buildings but the spaces that they create. "The wheel has thirty something spokes but it becomes useful on account of the hole in its centre. Fashion the pitcher with clay: it is its interior that is useful. Houses are not the 
walls but the empty space inside, which they enclose. Thus, the obvious is necessary and the undeclared is useful." (Lao Tzu [6]).

\section{References}

[1] http://en.wikipedia.org/wiki/Urban_planning. (As early as 2600 B.C. in India large cities were being constructed with build-up areas criss-crossed by grids of streets running parallel and perpendicular to each other, from north to south and east to west. Similar cities were also being built in Egypt, Babylon, China and Greece with its oldest city, Miletus -5th century B.C.having been planned by Hippodamus).

[2] P. Downton, Ecopolis: Architecture and cities for a changing climate, Springer, p 369, 2009.

[3] R. Toledano, Savannah, Architectural \& Cultural Treasures, Preservation Press, John Wiley\& Sons, INC, p 59, 1997.

[4] Rogers, R., et al., Urban Task Force, Towards an Urban Renaissance: Final Report of the Urban Task Force Chaired by Lord Rogers of Riverside. Department of the Environment, Transport and the Regions, London p 57, 1999.

[5] R. Arnheim, The dynamics of architectural form, University Studio Press, Thessaloniki pp 37-39, 2003.

[6] Lao Tzu 'Tao Te Ching', The book of Reason and of Nature, Smili Editions, Athens, p.35, 1996. 